\title{
From ergonomics to design specifications: contributions to the design of a processing machine in a tire company
}

\author{
Moraes, A. S. P. ${ }^{\mathrm{a}^{*}}$, Arezes, P.M. ${ }^{\mathrm{a}}$, and Vasconcelos, R. ${ }^{\mathrm{b}}$ \\ ${ }^{a}$ Department of Production and Systems Engineering, University of Minho, Campus de Azurém, 4800-073, \\ Guimarães, Portugal \\ ${ }^{\mathrm{b}}$ Faculty of Psychology and Educational Sciences, University of Porto, Rua Dr. Manuel Pereira da Silva \\ 4200-392, Porto, Portugal
}

\begin{abstract}
The development of ergonomics' recommendations, guidelines and standards are attempts to promote the integration of ergonomics into industrial contexts. Such developments result from several sources and professionals and represent the effort that has been done to develop healthier and safer work environments. However, the availability of large amount of data and documents regarding ergonomics does not guarantee their applicability. The main goal of this paper is to use a specific case to demonstrate how ergonomics criteria were developed in order to contribute to the design of workplaces. Based on the obtained results from research undertaken in a tire company, it was observed that the ergonomics criteria should be presented as design specifications in order to be used by engineers and designers. In conclusion, it is observed that the multiple constraint environment impeded the appliance of the ergonomics criteria. It was also observed that the knowledge on technical design and the acquaintance with ergonomic standards, the level of integration in the design team, and the ability to communicate with workers and other technical staff have paramount importance in integrating ergonomics criteria into the design process.
\end{abstract}

Keywords: ergonomics criteria, design process, design specifications, tire company

\section{Introduction}

The development of ergonomics' requirements, recommendations, guidelines and standards are attempts to promote the integration of ergonomics into industrial contexts. Industries, governments, associations and organizations have been striving to develop and apply human factors to new design projects or ongoing activities. The assumption underlined in this effort is that supplying ergonomics criteria to design will result in better workplaces and/or more efficient operations [11]. It is remarkable the importance that human factors can play in helping to avoid accidents and ill-health at work [10]. Regardless of the aforementioned efforts, the total number of occupational accidents and fatal work-related diseases has increased globally in the last decade [19]. The problem does not seem to be associated only with the availability of human factors information to designers [1].

It is important to consider that one of the reasons for the increasing trends of occupational accidents and work-related diseases numbers could be related to the lack of consideration on ergonomics criteria into design. In order to do so, it is important to realize how ergonomics criteria are developed by ergonomists. Secondly, it is essential to understand how the ergonomic criteria are perceived and used on real design contexts by design teams. Through this, it is possible to develop better ergonomics tools and methods, in order to increase the chance of an ergonomic criteria consideration on the design.

This study also represents an effort to understand the context on which a design process occurs. The research was carried out in a tire factory and presents

\footnotetext{
* Corresponding author. Address: Departamento de Produção e Sistemas - Escola de Engenharia/Universidade do Minho. Campus de Azurém. 4800-000. Phone: +351915 295 292. E-mail: sophiapiacenza@gmail.com
} 
a real engineering design process as case study. A particular design element, a mezzanine structure and its components, such as ladders and stairs, it is presented in this manuscript. The main objective is to demonstrate how ergonomic criteria were generated by the work analysis, perceived and applied by engineers and designers.

\section{Ergonomic requirements, recommendations, guidelines and ergonomics standards}

The goal of human factors design guidelines is to summarize human engineering data, recommendations, and principles to be used by designers, engineers, human factors practitioners, and others [13], either resulted from a specific work analysis or general standards.

Ergonomics work analysis provides a standpoint of malfunctioning, variability, and hazards that are found in workplaces. Ergonomics guidelines and recommendations are generally the outputs of an ergonomics analysis, and present particular recommendations according to the results obtained in a contextualized study, in specific work situations. From the ergonomics' point of view, guidelines and recommendations frame the 'desirable' workplace considering an 'ergonomically optimal' design. Ergonomics guidelines and recommendations are assumed by ergonomists as a 'should do' list.

From other perspective, ergonomics standards give general guidelines regarding ergonomic aspects. Organizations, associations and government agencies from all over the world have been striving to develop ergonomics standards and requirements [12]. Organizations such as CEN (European Committee for Standardizations), ISO (International Organization for Standardization), BSI (British Standards Institute) and OSHA (Occupational Safety and Health Administration) are a few instances. The standards developed by them consist in a clear attempt and effort to promote healthier and safer work environments.

\section{Critics about ergonomic recommendations and standards}

Some studies $[6,14,18]$ show that the large amount of existing data regarding ergonomics does not guarantee their application in the engineering design. Two reasons can justify the poor incorporation of ergonomic guidelines and standards into the design [13]: first, the growing information gap between the advanced and diverse status of human-machine systems and second the availability of human factors design criteria that can be used during the system design process.

Ergonomics is considered by designers as a 'fuzzy' discipline, providing vague recommendations [3]. A study [13] shows that designers see human factors reference materials as being "too wordy", "too general" and "too hard to understand". According to this study, despite the increased interest in the development of human factors design guidelines, there also remains considerable uncertainty and concern regarding the actual utility of such information.

\section{Case study: the design of a processing machine}

This study is based on the results of a research project undertaken at a large tire factory, where an engineering design team has been formed to refurbish and install a specific processing machine. It is important to highlight that a similar machine was already installed and operating in the factory where this study was made. The second machine that will be installed was used to operate in another factory of the same company. The machine was to be transferred from one factory to another. At this process the machine had been disassembled into basic parts. Also, during the refurbishment and installation of the machine, many modifications at some systems, especially the electrical components that were already obsolete, and also some improvements in specific apparatus such as the measurement sensors, were to be made. Also, other components and placement of the parts of the machine will be changed. Other parts, like the stairways, mezzanine floor and supports are needed to be built according to the new machine and the building where it would be installed.

\subsection{The phases of the study}

By applying a participatory action-research methodology [16], the study includes 2 main stages. The first one is focused on understanding the existing reference situation, similar to the one that would be designed. As soon there was already an operating machine at the plant that was similar to the one to be installed, the existing workplaces and activities could be used as a reference situation [8]. Also, some of the workers of the existing machine would be the work- 
ers of the new one. This represents, in terms of research, a particular opportunity.

The method of Ergonomic Analysis of Work Activity - EAWA, was used to understand the work and identify the main variables of the process. Special attention was given to process variability. During 4 months, observations and interviews were conducted with workers from different work shifts and workplaces. Also, a detailed analysis of documents available at the company was carried out, regarding the company procedures and the legislation mainly related to safety and health at work. The main purpose of this stage was drawing up a reference situation, in order to further, generate criteria to be applied to the design of the new machine.

The second stage was focused on the design of specific parts of the processing machine. The main objectives were developing ergonomic criteria, defining particular design specifications and incorporating them into the design of the new machine. This stage involved a larger number of intermediaries, especially the design team responsible for the design. The design team was formed by 1 engineer project leader, 2 electrical and mechanical technicians and 1 outsourced draughtsman. Interviews with the design team were conducted, and discussions were developed, according to the specific point to be designed. These discussions happened on real time, simultaneously with the design decisions. After this, participatory meetings were conducted with the workers from different shifts, in order to present them the final project design and to open the discussion about their own requirements and perceptions regarding the design

\subsection{The processing machine}

The cited processing machine, a calender, is mainly used to produce steel or fabric belts that are used as components for tires, such as body plies and belts. The machine constitutes a set of multiple largediameter rolls that squeeze thin rubber sheet, covering both sides of a textile fabric or steel cords. During the calendering, the adherence of the rubber with the cords are made by pressure and heating. The final products, steel cords or textile fabric, are usually of the order of 2 meters wide. Next, the products are sent to the cutting phase and then to the tire building.

The existing calender was installed in the plant in 1994. It produces 12 different products, using 2 different kinds of steel cords, 8 types of textile fabrics and 3 different rubber compounds. The machine is nowadays operated by 6 workers per shift, in 3 works shifts of 8 hours per day, 7 days per week. Currently, the machine operates in the upper limit of its capacity. With the installation of a second calender, the total production of calandering in the plant would be doubled, at least theoretically.

\section{A practical example concerning the design of the processing machine: the ladders, stairs and mezzanine floor}

One specific point about the design is presented in this paper, to demonstrate the aspects regarding the use of ergonomic requirements and standards: the ladders and stairways that allow workers to reach specific parts of the machine located above ground level, and the platforms that constitute the mezzanine floor.

As soon most of process plants maintain equipments above grade, this means that is required to be operated above ground level by workers. Ladders, stairs, ramps, walkways, and platforms are also important to guarantee the access of workers in these situations. Therefore, a proper design of stairs, ramps, ladders, walkways, and platforms can affect the safety and efficiency of work above grade [4].

The next sub items present the data obtained from the different phases of the study regarding specifically the design of ladders, stairs and walkways. In the end, results from the analysis of the data collected are presented.

\subsection{Drawing up the reference situation and generating criteria to the design: collecting data from different sources}

\subsubsection{Data obtained from the observation of work activities on the existing machine}

The existing machine has 2 stairs and 1 fixed ladder. The stairs connect the ground level to the platform level of the mezzanine and the ladder access the upper feedstock of the calender.

The main activities regarding the calendering are done mainly on the pavement level. Only one regular task depends on the use of a ladder: the removal of rubber compound from the feedstock located on upper rolls of the calender. This task is made regularly during the set-ups of products if the products on sequence use different kinds of rubber compounds. The set-ups depend on the production planning, but is averagely done 4 times per work shift. 
The removal of rubber compound can also happen in case of process variability, for example, when the machine stops for any reason, programmed or not. This is needed because letting the rubber on the feedstock can lead to its vulcanization and consequently causes loss of material. The elimination of rubber compounds from the feedstock is a task prescribed by the Work Instruction for Steel cord and Textile fabric Calendering, document prepared by the Department of Industrial Engineer of the company and available for consulting by the workers.

Some secondary activities depend greatly on the ladders, stairs and platforms of mezzanine floor. Examples of these are the predictive maintenance and cleaning activities. The maintenance and cleaning workers used to stand on the ladders, not only to access the mezzanine floor, but also as a work station. The specific place where the activity is done depends on where it is necessary to reach to execute the maintenance or the cleaning task. The predictive maintenance activities are done by 10 workers on average, during a work shift of 8 hours, carried out each 15 days. Cleaning activities are done by approximately 4 workers, from an outsourcing company, during the work shift of 8 hours. Cleaning activities are also carried out each 15 days, in the meantime of maintenance activities.

\subsubsection{Data obtained from integration and interviews with the design team members}

According to the design team, the main aspect regarding the design of the new machine was the intention to make it looks as similar to the existing one as possible. However, an analysis of the drawings and interviews with the design members revealed some already planned modifications on the design compared to the existing machine.

The main alteration regarding the stairs and ladders was their dimensions. The platforms of the mezzanine floor were planned to be reduced in $20 \mathrm{~cm}$, when compared to the existing ones. According to the responsible engineer, this could represent saving on the price of the project contract and less waste of material, because of dimensions of the initial material. The possible impact on the activities of the calender workers caused by this modification was not measured. When asked about the perception of workers regarding the ladders and stairs of the existing machine, the design team members affirmed that there were no specific complaints from workers.

About the use of ergonomic standards, the designer affirmed that they had no knowledge about the existence or need of applying design specific standards regarding ladders, stairs and platforms on the design. Also, there was no information regarding specific ergonomic standards or guidelines for ladders and stairs. Neither was any concern by the design team if the existing ladders, stairs and platforms were built according to ergonomic or general standards.

\subsubsection{Data obtained from participatory meetings}

During the participatory meetings, the calendering workers were taken to a private classroom. The meetings were repeated 3 times, in different days, to allow participation of workers from all work shifts, including the workers from the weekend shifts. Apart from the workers, only the ergonomist took part on the meetings.

During the participatory meetings, the final design of the structure with ladders, stairs and platforms of the mezzanine floor was presented to the workers. The design was presented to inform them how it was made by the design team, which included a three dimensional model and an engineering drawing. Both were presented to the workers in printed version and in a slide projection. Subsequently, the workers were able to discuss about the design proposal and main questions regarding the design. The purpose of this first stage was collecting the first impressions of the workers about the project. No comments were made by the ergonomist in order to obtain their first impressions and main worries about the global project. All the workers' comments were recorded. In a second phase of the meetings, the workers were asked specifically about the stairways, ladders and platforms. The main purpose was collecting their impression and their opinion regarding this specific point. Some specific questions were also made to validate the data obtained on the observation of work activity phase. The same protocol was made in all 3 participatory meetings.

According to the workers attending the participatory meetings, beyond the usage of ladder to remove rubber from the feedstock, they only use the stairs in case of a fabric get wrapped on the rolls, to reset the electrical system or to verify any kind of anomalies. They also remember that the use of stairs happens mainly in case of an emergency. In these cases, the workers usually need to run to check and solve the problems, in order to avoid any consequence and interruptions to the production line, and solve them in the less time possible. The workers also ensure that the main ladder used is the one that gives access to 
the upper feedstock of the machine. One of the workers affirmed that:

"I am used to going there (referring to the upper feedstock) many times".

Also, the workers agree on the fact that this ladder is the most unsafe of all the ladders and stairways of the machine, and they claimed that some workers already had some accidents on this ladder, including the ones with lost-time injuries. They also noted that the original project of the existing machine has only 2 stairways to the mezzanine floor, and the third one was made after a while, as a suggestion by the workers, made in a specific program to promote the workers suggestions.

In the second participatory meeting, workers suggested a change to the design: to invert the direction of the stairway, having as closest access from the pavement to the last workstation of the calender as possible. The worker allocated in this work station is the one that usually climbs the stairs to reset the electrical system. This would contribute to a faster access to the second level. Regarding the ladder to access the upper feedstock, the workers suggested to be as close to the machine as possible.

\subsubsection{Data obtained from an analysis of ergonomic standards and other normalizations}

After the interviews with the design team members, it was important to search the standards and directives that could be applicable to the design.

From the existing standards for use at company, only one regarding ergonomics would be applicable. The standard sets out ergonomic rules for designers taking into account the health and safety of the operator, in all areas of their activities. It consists of two parts:

- NP EN 614-1:1996 Safety of machinery. Ergonomic design principles. Part 1: Terminology and general principles;

- NP EN 614-2:2004 Safety of machinery. Ergonomic design principles. Part 2: Interactions between the design of machinery and work tasks.

Although the stairs, ladders and platforms were not mentioned in specific, some parts of the standard could be examined as applicable to their design. This is because the stairs, ladders and platforms, are sometimes used as a workplace or work station, principally by the cleaning and maintenance workers. However, this ergonomic standard provides general instructions regarding ergonomic criteria associated with the safety of machinery. However, both parts of this standard were already cancelled from the national normative body of the country. Both parts have been replaced by a newer version, published by European Committee for Standardizations:

- EN 614-1:2006 + A1:2009 Safety of machinery. Ergonomic design principles. Part 1: Terminology and general principles;

- EN 614-2:2000 + A1:2008 Safety of machinery. Ergonomic design principles. Part 2: Interactions between the design of machinery and work tasks.

In addition to general ergonomic standards, it was important to search in another sources, specific legislation, guidelines or minimum requirements that lay out the design of ladders, stairways, ramps, walkways and platforms. Specifically no standards exist within the company regarding ladders and stairways.

An open search on european and national legislation and standards databases found the following documents regarding stairs, ladders and platforms standards:

- Originally published by ISO in 2001. Enacted as european standard and translated as national standard in 2011:

* NP EN ISO 14122-1:2011 (Ed.1) Safety of machinery. Permanent means of access to machinery. Part 1: Choice of fixed means of access between two levels;

* NP EN ISO 14122-2:2011 (Ed.1) Safety of machinery. Permanent means of access to machinery. Part 2: Working platforms and walkways;

* NP EN ISO 14122-3:2011 (Ed.1) Safety of machinery. Permanent means of access to machinery. Part 3: Stairs, stepladders and guardrails.

- Originally published by ISO, enacted as european standard in 2004, but not adopted as national standard:

* EN ISO 14122-4:2004/A1:2010 (Ed.1) Safety of machinery - Permanent means of access to machinery. Part 4: Fixed ladders.

- Originally published by CEN in 2007, enacted as European Standard, adopted as national standard:

* EN 131-1:2007 (Ed.2) Ladders. Part 1: Terms, types, functional sizes;

* EN 131-2:2010 (Ed.2) Ladders. Part 2: Requirements, testing, marking;

* EN 131-3:2007 (Ed. 1) Ladders. Part 3: User Instructions;

* EN 131-4:2007 (Ed. 1) Ladders. Part 4: Single or multiple hinge-joint ladders. 
Also, there is a regulation published by the Occupational Safety and Health Administration (OSHA 29 CFR 1926.1050-1060) that aim the design and use of ladders. Also a special edition of a guide to appliance of OSHA Rules for Stairways and Ladders (OSHA 3124-12R 2003) has been published.

Concerning the European directives, the only one available at the company was:

- 98/79/EC - 98/37/EC Machine Directive: States that machinery design must take into account ergonomic principles, so that the discomfort, fatigue and psychological stress of the operator is minimized.

Again, and open research found another European Directives that could be applicable to the case:

- 89/391/EEC: A general framework directive. Obliges employers to take necessary measures to safeguard worker's safety and health in every aspect of their work;

- 89/654/ECC: Concerns minimum safety and health requirements both for workplaces currently in use and the ones used for the first time. Special topics concerning freedom of movement at workstations;

- 2006/42/EC: States essential health and safety requirements related to the design and construction of machinery.

\subsubsection{Data obtained from other references}

Also, ergonomics textbooks were used as a source of practical recommendations related to ergonomics and the design specifications regarding stairs, ladders and platforms.

A manual provides main instructions regarding stairs and ladders, and recommends the type of stair/ladders more appropriated for the angle of ascent/descent. Also it is suggested to provide handrail and guarantee the access to the workstation for maintenance and as an emergency escape. This manual also gives a special attention regarding the item maintainability, suggesting the incorporation of the design for maintainability into main design procedure [7].

Another textbook [5] reinforces the anthropometric and biomechanical considerations when the operators needs to move between different levels, and suggest a preference for the use of ramps, since it's safer and easier to use regarding energy cost and the possibility of carryin gloads between levels. Regarding stairs, an attention to 4 aspects of their geometry is suggested in the manual that appears to be most important in determining their ease and safety:
- the riser height (the vertical distances between steps);

- the tread depth (the distance between the front and the back of the step);

- the steepness (slope) of the stairs;

- the tread texture.

The first three factors determine the amount of energy required, and the fourth affects the likelihood of slipping.

Other manual [4] advices the most important design issues regarding ladders, stairs and ramps. It is suggested that the design and use of a ramp, stairway, or a ladder depends on two major issues: the angle of ascent/descent and the nature of the task. This manual also suggests the preference for stairs instead of ladders, in some cases, like the frequency of usage. It states that "stairs, not ladders, should be installed, if:

- personnel are required to carry large tools or pieces of equipment upon down the structure;

- equipment must be accessed or personnel evacuated during emergencies (e.g., battery limit stations);

- hazardous material must be carried manually between levels;

- equipment is frequently accessed (at least once per shift on the average).

Other recommendations found in relevant literature [15] remark the dimensional uniformity between successive risers and treads, a proper placement of handrails, the use of a nonslip surface on tread surfaces and enhanced visibility of the tread nose edges.

\subsection{Results obtained from the data collection and their appliance on the design}

As soon this study was planned to follow an action-research methodology, the data collected during the first phases intended to generate specific criteria to be used by the design team. The ergonomic criteria were developed from 4 different sources:

- direct observation of the work activities;

- informal and formal interviews with design team members;

- participatory meetings with the workers;

- analysis of specific and ergonomic standards, ergonomics manuals and textbooks.

The final purpose of the research was applying these criteria to design of the machine. However, some impediments have led to a failure in using the criteria into the design. First, the impact of project timing as a dominant constraint is remarkable. As soon the study at the company started after the begin- 
ning of the design process, some decisions were already made. Because the drawings should be sent to outsourcing companies for budgeting, a delay of the project time would cause other impacts on the project schedule.

Still regarding the time, the design team stated a possibility of changing the final design if necessary, after the budgeting phase. However, it is evident that modifications to the design would imply rework, time loss and extra-cost. An evaluation of the costs and benefits [9] of the changes proposed could have facilitated a review on the design and the incorporation of ergonomic criteria.

The participatory meetings also contributed to a delay in providing results to the design team. It is also evident that participatory processes take longer than non-participatory ones, or that they usually has no set end date [16]. As soon the participatory meetings were only possible to take place every 15 days when the calender workers were available to join the meetings during their work shift, and the production stops for maintenance and cleaning - they took around 45 days to be concluded with 3 work shifts.

In addition, since the participation of workers only took place in a late phase of the design process, the only possible input was through an evaluation of the final design. The lack of integration between workers and the design team, since the beginning of the design process, hampered a common construction of the design solutions. The late integration of the ergonomist into the design team also reduced the possibilities of change on the design. An earlier integration with the design team could have helped and facilitated the appliance of the ergonomics criteria in the design. This demonstrate the importance of a consideration of ergonomics since the first stages of the design process, when fewer decisions were already made, and the possibilities were broader.

During the participatory meetings, the workers claimed that the final drawings were not detailed enough. As soon the drawings were made with the purpose of the selection of an outsourcing company, they consisted in only the design of the structure with platforms and ladders. Most parts of the machine were not showed at the drawing. According to the machine workers, it was hard to have a more precise idea about the final design and final aspect of the machine after the installation. Due to the level of details of the drawings, the workers claimed that they could not make anymore suggestion regarding the stairs and platforms. In the participatory meetings not typical situations were stressed, and concrete solutions to the design were proposed by the workers.
The dimension reduction on the mezzanine platforms shows clearly how ergonomics criteria were competing with other criteria on the design. In this case, it was a cost criterion. Concerning the impact of the reduction of the platforms width on the mezzanine floor, the most impacted ones would be the maintenance and the cleaning workers. As soon the cleaning workers are from an outsourcing firm, the access to them was difficult. The supervisor responsible for the cleaning company did not declare any difficulty or complain from the workers regarding their difficulties. A detailed study regarding the activities of the cleaning workers was needed to be negotiated with the outsourcing company and with the contract manager of the company. The maintenance workers, even being from the company, were also difficult to contact. Their tight work schedules impeded their inclusion on the participatory meetings and the interviews were conducted during their work activities.

Concerning the data obtained from standards, it was evident that the existing information was not satisfactory. Only one standard available at the company could be applied to the design of ladders and stairs. The standard stated general instructions regarding ergonomic aspects or work places. The design team was not aware of the existence of this standard. Other specific standards were not available at the company. This requires buying these standards, which would represent an extra-cost to the project. Also, the applicability and the benefits obtained from their use of them on the design were not clear from the ergonomic point of view.

\section{Conclusions}

Ergonomic criteria are either obtained from specific work analysis or ergonomics standards and guidelines. They intend to help the design, contributing to the development of healthier, safer and more efficient work places. However, to be adopted by engineers and designers, the ergonomics criteria need to be presented as clear and practical design specifications. Otherwise, they may not be implemented.

Some of the reasons for not implementing the ergonomic criteria into design are related to the fact that engineering design process happens in a rich constraint environment. Designer and ergonomists must negotiate through a changing web of constraints from many sources, and constraints can justify why the 'best' ergonomic design is not always adopted [2]. 
Also the formal organization of human factors or the ergonomics criteria may not be fully known by project design members of the companies [11].

Another reason that can justify the poor incorporation of ergonomics into design can particularly be related to how ergonomics criteria are generated and presented by ergonomists. Also the way by which the ergonomic standards are perceived and used by engineers and designers should be more apprehended. The integration between ergonomists, design team members and workers in a participatory process could improve the appliance chances of ergonomics criteria.

The case study shows that the participation of an ergonomist is a possible key to engender and apply ergonomics criteria into the workplace design. Otherwise, those criteria are unlikely to be considered in the design of work environments. In the present case study, a work analysis was fundamental to generate specific criteria to the design of some components of a processing machine. Also participatory meetings with the workers enriched the analysis, highlighting particular points of view and allowing all the workers to contribute to the design of their future work place. The search and analysis of available standards and guidelines regarding ergonomics also brought other criteria to the design.

The ability of ergonomist to choose and apply specific methods and tools according to the stage of the engineering design process seems to be fundamental to enhance the visibility and impact of ergonomics criteria into the design case. In conclusion, it is observed that the knowledge on technical design and the acquaintance with ergonomic standards, the level of integration in the design team, and the ability to communicate with engineers and workers are primordial to help translating ergonomics criteria into design specifications. As stated [17] the apparent entrenched failure to incorporate ergonomics adequately in designs should be a reminder to ergonomists that we still have a long way to go before we can assume that even the most basic ergonomics issues are readily understood and utilized by all designers and engineers. Being presented as clear design specifications, the ergonomics may fulfil their main objective and contribute, in a consistent way, to the design of work equipments and work places.

\section{References}

[1] C. Burns and K.J. Vicente, Judgements about the value and cost of human factors information in design, Information Processing \& Management 32, 3 (1996), 259-271.

[2] C. Burns and K.J. Vicente, A participant-observer study of ergonomics in engineering design: how constraints drive design process, Applied Ergonomics 31 (2000), 73-82.

[3] C.M. Haslegrave and K. Holmes, Integrating ergonomics and engineering in the technical design process, Applied Ergonomics 25 (1994), 211-220.

[4] D.A. Attwood, J.M. Deeb and M.E. Danz-Reece, Ergonomic solutions for the process industries, Elsevier, Boston, 2004.D.J. Oborne, Ergonomics at work, $2^{\text {nd }}$ ed., John Wiley, Chichester, 1987.

[5] E. Fadier and J. Ciccotelli, How to integrate Safety in Design: Methods and Models, Human Factors and Ergonomics in Manufacturing 9 (1999), 367-379.

[6] E.N. Corlett and T.S. Clark, The ergonomics of workspaces and machines: a design manual, $2^{\text {nd }}$ ed., Taylor \& Francis, Bristol, 1995.

[7] F. Daniellou, Simulating future work activity is not only a way of improving workstation design, @ ctivités 4:2 (2007), 84-90.

[8] H.W. Hendrick, Determining the cost-benefits of ergonomics projects and factors that lead to their success, Applied Ergonomics 34 (2003), 419-427.

[9] Health and Safety Executive (HSE), Reducing error and influencing behavior, $2^{\text {nd }}$ ed., HSE Books, Suffolk, 1999.

[10]I.A. Wulff, R. H. Westgaard and B. Rasmussen, Ergonomic criteria in large scale engineering design I. Management by documentation only? Formal organization vs. designers'perceptions, Applied Ergonomics 30 (1999), 191-205.

[11]I.A. Wulff, R.H. Westgaard and B. Rasmussen, Ergonomic criteria in large scale engineering design II. Evaluating and applying requirements in real world of design, Applied Ergonomics 30 (1999), 207-221.

[12]J.L. Campbell, The development of human factors design guidelines, International Journal of Industrial Ergonomics 18 (1996), 363-371.

[13]L. Cordiner and R.J. Graves, Ergonomic intervention during a gas processing plant refurbishment, International Journal of Industrial Ergonomics 19 (1997), 457-470.

[14] M.S. Sanders and E.J. McCormick, Human Factors in Engineering and Design, 7th ed., McGraw-Hill, New York, 1993.

[15]M. Walter, Participatory Action Research, in: Social Research Methods, $2^{\text {nd }}$ ed., M. Walter, ed., Oxford University Press, Australia, 2009, 21.

[16]N. Skepper, L. Straker, and C. Pollock, A case study of the use of ergonomics information in a heavy engineering design process, International Journal of Industrial Ergonomics 26 (2000), 425-437.

[17] O. Broberg, Integrating Ergonomics Into Engineering: Empirical Evidence and Implications for the Ergonomists, Human Factors and Ergonomics in Manufacturing 17 (2007), 353-366.

[18]P. Hämäläinen, K.L. Saarela and J. Takala, Global trend according to estimated number of occupational accidents and fatal work-related diseases at region and country level, Journal of Safety Research 40 (2009), 125-139. 